\title{
Immediate versus delayed frozen embryo transfer in women following a failed IVF-ET attempt: a multicenter randomized controlled trial
}

Jing-Yan Song ( $\square$ hanlingjuzei91@126.com )

Shandong University of Traditional Chinese Medicine https://orcid.org/0000-0002-2700-017X

\section{Feng-Yi Dong}

Jinan Maternity and Child Care Hospital Affiliated to Shandong First Medical University

Li Li

Shandong University of Traditional Chinese Medicine

Xing-Xing Zhang

Maternity and Child Health Care of Zaozhuang

Ai-Juan Wang

Shandong University of Traditional Chinese Medicine Second Affiliated Hospital

\section{Yi Zhang}

Shandong University of Traditional Chinese Medicine

\section{Dan-Dan Gao}

Shandong University of Traditional Chinese Medicine

Ji-Mei Xiao

Heze Hospital of Traditional Chinese Medicine

Zhen-Gao Sun

Shandong University of Traditional Chinese Medicine Affiliated Hospital

\section{Research Article}

Keywords: infertility, frozen embryo transfer, in vitro fertilization, ongoing pregnancy, psychological stress

Posted Date: July 23rd, 2021

DOI: https://doi.org/10.21203/rs.3.rs-738847/v1

License: (-) This work is licensed under a Creative Commons Attribution 4.0 International License. Read Full License 


\section{Abstract \\ Background}

The optimal time at which to perform a frozen-thawed embryo transfer (FET) following a failed in-vitro fertilization-embryo transfer (IVF-ET) attempt remains elusive to most reproductive experts. Physicians often delay the introduction of FET due to concerns related to potential residual effects of ovarian hyperstimulation which may interfere with the regular menstrual cycle. Moreover, given that most of the published studies on the topic are retrospective and have inconsistent findings, it is crucial to develop evidence-based randomized control guides for clinical practice. Therefore, this well-designed randomized controlled trial (RCT) was conducted to determine whether it is necessary to delay FET for at least one menstrual cycle after the failure of fresh embryo transfer.

\section{Methods}

Infertile women eligible for IVF-ET were invited to participate in this multicenter, randomized, non-inferiority, parallel-group, unblinded, controlled trial at the academic fertility centers of four public hospitals in Chinese Mainland. Infertile women scheduled to receive their first FET cycle after a failed IVF-ET attempt were randomly assigned to either (a) the immediate FET group in which FET was performed in the first menstrual cycle following the failed IVF-ET cycle $(n=366)$ or $(b)$ the delayed FET group in which FET was performed in the second or subsequent menstrual cycle following the failed IVF-ET cycle $(n=366)$. All FET cycles were performed during hormone replacement cycles for endometrial preparation. The primary outcome was the ongoing pregnancy, defined as a detectable fetal heart beat beyond twelve weeks of gestation. Secondary outcomes were other pregnancy-related outcomes, maternal and neonatal complications. Analysis was performed by both intention-to-treat and per-protocol principles.

\section{Results}

A total of 646 FETs were completed. The frequency of moderate to severe depression and high stress level prior to FET in delayed FET group were significantly higher than that in immediate FET group $(10.6 \%$ vs $6.1 \%$, $p=0.039 ; 30.3 \%$ vs $22.4 \%, p=0.022$, respectively). Immediate FET resulted in a higher frequency of clinical pregnancy than did delayed FET ( $41.7 \%$ vs $34.1 \%$ ), for a relative risk (RR) of 1.23 (95\% confidence interval [Cl], 1.00-1.50; $p=0.045$ ). Women who underwent immediate FET also had a lower frequency of biochemical pregnancy loss $(11.7 \%$ vs. $30.6 \%)$, with a RR of $0.28(95 \% \mathrm{Cl} 0.23-0.63, \mathrm{p}<0.001)$, and a higher frequency of embryo implantation $(25.2 \%$ vs. $20.2 \%)$, with a RR of $1.25(95 \% \mathrm{Cl} 1.01-1.53 ; \mathrm{p}=0.038)$. Although the ongoing pregnancy and live birth rates did not differ significantly between the immediate FET and delayed FET groups (37.1\% vs $30.3 \%$, RR $1.22,95 \% \mathrm{Cl} 0.99-1.52$, $\mathrm{p}=0.067 ; 36.5 \%$ vs $30.0 \%$, RR $1.22,95 \% \mathrm{Cl} 0.98-$ $1.52, p=0.079$, respectively), a multivariate logistic regression analysis adjusted for potential confounders such as depression and stress levels revealed that the immediate FET group had a significantly higher ongoing pregnancy and live birth rates than the delayed FET group (odds ratio $0.68,95 \% \mathrm{Cl} 0.47-0.99, \mathrm{p}=$ 
0.041 ; odds ratio $0.67,95 \% \mathrm{Cl} 0.46-0.96, \mathrm{p}=0.031)$. The risks of maternal and neonatal complications were comparable between the two groups.

\section{Conclusions}

In women with a previous failed IVF-ET attempt, immediate FET resulted in higher ongoing pregnancy and live birth rates than delayed FET. These findings warrant caution in the indiscriminate application of a delayed FET strategy when apparent risk of high stress level is perceived.

\section{Background}

The last three decades have witnessed growing success with frozen embryo transfer (FET). Currently, deferred embryos and cryopreservation are essential aspects of IVF/intracytoplasmic sperm injection (ICSI) treatment $[1,2]$. However, the findings of the perinatal outcomes in fresh or frozen embryo transfers are controversial. Notably, FET has been associated with lower rates of antepartum hemorrhage [3], preterm birth, ectopic pregnancy [4-7], and low birth weight [3, 8-10]. Nonetheless, FETs have been linked to higher rates of placental/hypertensive complications [7], large-for-gestational-age infants [7, 11], and inconclusive perinatal mortality rates $[3,11]$. Therefore, given the setbacks, most researchers are skeptical of the overall benefits of FET [12-15]. Moreover, physicians face the question of ovarian hyperstimulation and the long-term effects of subsequent FET treatment [16]. As such, FET is often postponed in an attempt to minimize the possible residual effects of ovarian hyperstimulation on endometrial receptivity [17]. However, research on this area remains limited $[18,19]$. Deferrals of the FET treatment by physicians, even with the best of intentions, might frustrate couples.

There is limited evidence on the "perfect" timing for FET following a failed-fresh stimulated IVF cycle. However, two options exist, including i) perform FET during the first cycle (an immediate embryo transfer) ii) postpone for at least one menstrual cycle (a delayed embryo transfer). Two studies showed no differences in live birth rates or clinical pregnancies between delayed and immediate FET following a failed fresh IVF [20, 21]. According to Mass $\mathrm{K}$ et al., FET should not be postponed following fresh ET failure [17]. However, according to Volodarsky-Perel et al., FET should be postponed for at least one menstrual cycle after a failedfresh cycle [22]. Women whose attempt at pregnancy fails after a fresh embryo transfer (ET) during a stimulated IVF cycle often opt to proceed with FET immediately to get pregnant as soon as possible. Delaying FET is considered less patient-friendly as it adds to the stress and anxiety accompanying the IVF treatment. Therefore, given the contradictory reports, we conducted this RCT to provide evidence on ongoing pregnancy rate with immediate versus delayed FET following a failed-fresh cycle. We hypothesised that the pregnancy outcomes in immediate FET were non-inferior to that in delayed FET.

\section{Methods}

\section{Trial Design}


This study was a multicenter, randomized, controlled, parallel-group clinical trial conducted at academic fertility centers of four public hospitals in the Chinese Mainland. The study enrolled a total of 732 women with a planned transfer of good-quality vitrified-warmed embryos between May 2020 and July 2021. The study was approved by the ethics committees of the participating hospitals. All couples provided voluntary written informed consent before participation. The study protocol was as previously published [23]. This trial was registered with chictr.org.cn (Identifier: ChiCTR2000033313). Final live birth outcomes were available in June 2021. The data were reviewed and approved by an external Data and Safety Monitoring Board.

\section{Eligibility Criteria}

Individuals were screened for eligibility. The inclusion criteria were: women aged 21-43 years at the time of IVF/ICSI treatment, participants undergoing IVF/ICSI treatment with a standard controlled ovarian stimulation (COS) protocol, participants had at least one frozen embryo remaining for transfer and had the initial FET cycle after a failed fresh ET. The exclusion criteria were: women with a body mass index $(\mathrm{BMI}) \geq 28 \mathrm{Kg} / \mathrm{m}^{2}$, women with a natural cycle or mild stimulation for IVF/ICSI treatment, severe ovarian hyperstimulation syndrome (OHSS) during COS, history of unilateral oophorectomy or recurrent pregnancy loss, previously diagnosed with congenital or acquired uterine abnormalities, undergoing blastocyst biopsy for preimplantation genetic testing (PGT) or preimplantation genetic diagnosis (PGD), in vitro maturation (IVM) carried out, use of donor oocytes, or presence of hydrosalpinx, ovarian endometriosis cyst, or endometrial polyps that were not surgically treated. Eligible women signed a written consent form after counseling.

\section{Randomization and Blinding}

Women undergoing the initial FET cycle after a failed-fresh ET cycle were randomized into two groups (immediate FET and delayed FET) according to a computer-generated randomization list. Randomization was conducted 14 days after fresh ET (negative blood $\beta$-hCG test) for participants with a failed-fresh ET cycle. In addition, randomization was conducted by the project nurse, who was blinded from the entire recruitment and clinical management of the participants. The participants were allocated to four blocks and randomized using random numbers generated using SPSS software (Version 26.0, IBM Corp., Armonk) and were placed in opaque envelopes. Finally, participants were randomized into one of two groups: 1) The immediate FET group in which FET was performed after the first menstrual cycle following a failed-fresh ET cycle; 2) The delayed FET group in which FET was performed after two or more menstrual cycles following a failed-fresh ET cycle. Due to the nature of the intervention, we did not blind the participants, doctors, or trial outcome assessors on the assigned groups.

\section{Trial Protocols}

Women underwent IVF/ICSI treatment in the fertility centers as clinically indicated. Standard COS protocol with gonadotrophins was performed using a gonadotrophin-releasing hormone $(\mathrm{GnRH})$ antagonist protocol. Furthermore, a fixed GnRH antagonist (GnRH-ant) (0.25mg, Cetrorelix; Merck Serono, Darmstadt, Germany) was used together with 112.5-225 IU/day of recombinant FSH (600IU, Puregon, Merck Sharp \& Dohme B.V., Haarlem, Netherlands). The gonadotropin doses were determined based on individual patient characteristics. The oocyte retrieval was conducted under ultrasound transvaginal guidance, 34-36 hours after triggering with recombinant hCG $\left(250 \mu \mathrm{g}\right.$, Ovitrelle ${ }^{\circ}$, Merck Serono S.p.A., Italy). After that, conventional IVF/ICSI was carried out depending on the partner's semen quality per the standard protocols at the centers. Normal 
fertilization was assessed (a second polar body and two pronuclei) after 16-18 hours of conventional insemination or ICSI. Notably, an embryo with at least seven cells (grades $\nabla$ and $\Downarrow$ ) on the third day after oocyte retrieval was defined as good quality. In addition, embryos with at least six cells with fragments $<50 \%$ were considered frozen. According to the standard protocol, all "good" embryos were vitrified using the cryopreservation method on the third day.

Hormone replacement treatment (HRT) was used for endometrial preparation. Treatment with estradiol valerate ( $E_{2}$, Progynova, Schering AG, Berlin, Germany) was commenced on the third day of the menstrual cycle at 4-6mg daily for 10-12 days. Moreover, vaginal progesterone (90mg, $8 \%$ Crinone, Merck-Serono, Switzerland) was administered at a dose of $90 \mathrm{mg}$ per day, upon the endometrial layer reaching a thickness of $8 \mathrm{~mm}$ as revealed by pelvic ultrasound scanning. FET using three-day-old embryos was also scheduled on the fourth day of commencing treatment with vaginal progesterone. Furthermore, one or two embryos with the best morphology were transferred using a soft embryo-transfer catheter under ultrasound guidance. Finally, the serum $\beta$-hCG levels were determined fourteen days following FET. The hormone therapy was stopped when the serum $\beta$-hCG was negative. Luteal phase support (using estradiol valerate $6 \mathrm{mg}$ daily and vaginal progesterone gel $90 \mathrm{mg}$ daily) was continued in a transvaginal-ultrasound confirmed pregnancy until ten weeks of gestation. The maternal and neonatal outcomes of the initial FET were obtained through a review of medical records.

\section{Assessment for depression and stress}

Standardized and validated questionnaires were administered to the study participants to assess depression and stress before the FET. The participants were asked to complete self-administered questionnaires determining major depression index[24, 25]. The symptoms were rated on a 6-point Likert scale. The scale determines how long the symptoms have been present during the past 14 days. The scale ranges from 0 (no depression) to 50 (extreme depression). It corresponds to the diagnostic criteria for depression in the Diagnostic and Statistical Manual of Mental Disorders (DSM-IV) (including an additional item of low selfesteem) and the International Classification of Diseases and Related Health Problems (ICD-10). Study participants were categorized into four in accordance to the ICD-10 depression categories: mild (two to three core symptoms and two to three additional symptoms); moderate (two core symptoms and four or more additional symptoms); and severe (three core symptoms and five or more additional symptoms). Participants who did not fulfill any of these criteria were categorized as 'no depression'.

Emotional stress was assessed using the Cohen's Perceived Stress Scale. The participants completed a 10item self-report questionnaire consisting of a 5-point Likert scale. The final score ranged from 0 (no stress) to 40 (extreme stress). The PSS scale was designed to assess the degree to which respondents found their lives unpredictable, uncontrollable, or overwhelming [26]. The PSS scale was designed for comparisons between groups and is not a diagnostic tool. The PSS scores were dichotomized into $<19$ or $\geq 19$, where the latter represents 'high stress' based on a previous publication [27].

\section{Trial Outcomes}

The primary outcome was an ongoing pregnancy rate, which included natural conception. Ongoing pregnancy was defined as an intrauterine detectable fetal heartbeat after more than twelve weeks of gestation. 
Secondary outcomes were positive pregnancy rates, pregnancy loss rates, embryo implantation rates, ectopic pregnancy rates, multiple pregnancy rates, live birth rates, pregnancy-related complications, and obstetric complications. Maternal and neonatal outcomes, including preeclampsia, gestational diabetes, gestational hypertension, preterm delivery, low birth weight, infants born small or large for gestational age, and congenital anomalies, were recorded in pregnancies that continued beyond twenty weeks. Supplementary Table S5 provides definitions of all secondary outcomes.

\section{Statistical analysis}

The trial was designed as a non-inferiority study. The PASS software version 11.0 (NCSS, LLC. Kaysville, Utah, USA.) was used to determine the sample sizes for both groups. Notably, the ongoing pregnancy rate per embryo transfer was about $30 \%$ based on data from our reproductive center at the time of the trial design. The sample size calculation revealed that 329 women were to be included in each trial group to provide an $80 \%$ power to detect a minimal difference of $10 \%$ points between the immediate and delayed FET groups for the primary outcome of ongoing pregnancy ( $40 \%$ vs. $30 \%$ ) at a two-sided a level of 0.05 . Finally, the trial planned to include 732 women, with 366 participants in each arm to account for an expected $10 \%$ lost to follow-up.

Per protocol (PP) principle was used for the primary statistical analysis. Primary and secondary outcomes were assessed by comparing outcomes after the initial FET cycle. All women in an intention-to-treat (ITT) analysis were accounted for in the group to which they were randomised, irrespective of whether or not they received the treatment. The PP analysis included all women who adhered strictly to the study protocol. The as-treated analysis included women randomized to the immediate FET group who had immediate FET at the first menstrual cycle after a failed fresh ET and women randomized to the delayed FET group who received delayed FET at the second or subsequent menstrual cycle after a failed fresh ET. The ongoing pregnancy rate was determined, and relative risk was used to determine the difference. PP analyses were also performed for all reproductive outcomes. Continuous data were compared using Student's t-test, and the results were presented as mean (standard deviation) or median (interquartile range). Categorical data were assessed using $\chi^{2}$ analysis and Fisher's exact test for expected frequencies less than five. A two-sided $P$ value of less than 0.05 was considered statistically significant. Data analyses were conducted using SPSS version 26.0 and R statistical package version 4.0.0.

Multivariable logistic regression analysis was performed to determine variables independently associated with ongoing pregnancy, live birth, clinical pregnancy, or positive pregnancy and affecting outcomes. Female gender, age (<35 yrs., $\geq 35 \mathrm{yrs}$.), anti-müllerian hormone (AMH) $(<1.2 \mathrm{ng} / \mathrm{ml}, \geq 1.2 \mathrm{ng} / \mathrm{ml}), \mathrm{BMl}\left(<24 \mathrm{~kg} / \mathrm{m}^{2}, \geq\right.$ $\left.24 \mathrm{~kg} / \mathrm{m}^{2}\right)$, follicle-stimulating hormone (FSH) ( $\left.<10 \mathrm{UI} / \mathrm{L}, \geq 10 \mathrm{UI} / \mathrm{L}\right)$, antral follicle count (AFC) $(<10, \geq 10)$, endometrial thickness before FET, No. of oocytes retrieved $(\leq 9,>9)$, No. of transferred frozen-thawed embryos (single, double), method of fertilization (IVF, ICSI), moderate/severe depression prior to FET (yes, no), and high-stress levels prior to FET (yes, no) were included in the analysis.

\section{Results}

\section{Enrolled Patients and Baseline Characteristics}


A total of 1,212 individuals were screened for study enrollment. However, only 732 individuals gave an informed consent and were finally enrolled in the study. The participants were randomly assigned in a 1:1 ratio to the immediate or delayed FET groups (Fig. 1). A total of 732 FET cycles were available for the ITT analysis. Of these, 86 did not undergo embryo transfer or were disqualified per protocol, leaving 646 embryo transfer cycles for the PP analysis. This was commonly due to inadequate endometrial response to estrogen stimulation, $n=30$; personal reasons, $n=22$; lack of available embryos survival after thawing, $n=7$; the presence of endometrial polyps, $n=5$; the need for salpingectomy, $n=5$; unexpected ovulation, $n=7$; the presence of functional cysts, $n=7$; or spontaneous pregnancy, $n=3$. The canceled embryo transfers or the study disqualifications did not differ significantly between the immediate and delayed FET groups (10.9\% vs. $12.6 \%, p=0.491)$.

No significant differences in the baseline characteristics (including female gender, age, etiology /duration of infertility, BMI, nulliparity, gravidity, parity, $\mathrm{AMH}$, total AFC, basic FSH, basic luteinizing hormone (LH), and basic estradiol) were observed between the two groups (Table 1). The number of days of COS, total gonadotrophin dose administered, method of fertilization, number of oocytes retrieved, number of embryos available for transfer, number of high-quality day three embryos, and the number of embryos transferred in fresh ET cycle were comparable between the two groups (Table 1). The average number of frozen-thawed embryos transferred ( 2 vs. $2, p=0.956)$ and endometrial thickness before FET $(10.5 \mathrm{~mm}$ vs. $10.3 \mathrm{~mm}, \mathrm{p}=$ 0.388) were comparable between the immediate and delayed FET groups. The average FET time intervals for immediate and delayed FETs were 25.2 days and 103.5 days, respectively. (Table 1 ) 
Table 1

Basal demographic and cycle features of FETs which proceeded either within the immediate cycle following OPU (Immediate FET group) or subsequently (Delayed FET group) after a failed-fresh ET. Data are presented as numbers $(\%)$ unless otherwise noted.

\begin{tabular}{|c|c|c|c|}
\hline Characteristic & $\begin{array}{l}\text { Immediate FET } \\
\text { group }\end{array}$ & $\begin{array}{l}\text { Delayed FET } \\
\text { group }\end{array}$ & $\begin{array}{l}P \text { - } \\
\text { value }\end{array}$ \\
\hline Randomized subjects & 366 & 366 & \\
\hline Female age at oocyte retrieval (years; mean (SD)) & $33.8(3.2)$ & $33.3(4.1)$ & 0.062 \\
\hline Etiology of infertility & & & 0.815 \\
\hline Tubal factor & $184(50.3)$ & $177(48.4)$ & \\
\hline Anovulation & $43(11.7)$ & $36(9.8)$ & \\
\hline Male factor & $59(16.1)$ & $63(17.2)$ & \\
\hline Combined factor & $68(18.6)$ & $75(20.5)$ & \\
\hline Unexplained sterility & $12(3.3)$ & $15(4.1)$ & \\
\hline FET interval (days; mean (SD)) & $25.2(5.4)$ & $103.5(23.3)$ & $\hat{0}_{0.001}$ \\
\hline Duration of infertility (years; median (IQR)) & $4(4)$ & $5(2)$ & 0.817 \\
\hline Nulliparous & $176(48.1)$ & $180(49.2)$ & 0.767 \\
\hline Gravidity (median (IQR)) & $1(2)$ & $1(2)$ & 0.978 \\
\hline Parity (median (IQR)) & $0(1)$ & $0(1)$ & 0.844 \\
\hline $\mathrm{BMI}\left(\mathrm{kg} / \mathrm{m}^{2} ;\right.$ mean $\left.(\mathrm{SD})\right)$ & $23.1(2.9)$ & $23.5(2.9)$ & 0.116 \\
\hline AMH (ng/ml; median (IQR)) & $2.9(1.6)$ & $3.1(1.2)$ & 0.354 \\
\hline Basic FSH (mlU/ml; mean (SD)) & $6.7(1.0)$ & $6.8(1.9)$ & 0.920 \\
\hline Basic LH (mlU/ml; mean (SD)) & $5.0(1.5)$ & $5.0(1.2)$ & 0.688 \\
\hline Basic estradiol (pg/ml; median (IQR)) & $35.4(7.0)$ & $35.3(8.4)$ & 0.755 \\
\hline Total AFC (mean (SD)) & $10.4(3.2)$ & $10.7(2.9)$ & 0.329 \\
\hline No of days of COS (mean (SD)) & $10.7(2.1)$ & $10.9(1.8)$ & 0.132 \\
\hline Total Gn dose administered (IU; mean (SD)) & $2140.5(469.3)$ & $2180.5(551.2)$ & 0.291 \\
\hline Method of fertilization & & & 0.875 \\
\hline IVF & $247(67.5)$ & $245(66.9)$ & \\
\hline ICSI & $119(32.5)$ & $121(33.1)$ & \\
\hline No of oocytes retrieved (mean (SD)) & $10.5(2.1)$ & $10.7(2.8)$ & 0.170 \\
\hline No of embryos available for transfer (median (IQR)) & $5.5(2)$ & $5(5)$ & 0.235 \\
\hline
\end{tabular}


Table 2

Pregnancy and birth outcomes compared between the immediate and delayed FET groups. Data are presented as numbers (\%).

\begin{tabular}{|c|c|c|c|c|c|c|c|c|}
\hline & \multicolumn{4}{|c|}{ Intention-to-treat analysis } & \multicolumn{4}{|c|}{ Per-protocol analysis } \\
\hline & $\begin{array}{l}\text { Immediate } \\
\text { FET group }\end{array}$ & $\begin{array}{l}\text { Delayed } \\
\text { FET } \\
\text { group }\end{array}$ & $\begin{array}{l}\text { Relative } \\
\text { risk } \\
\text { (95\% } \\
\text { Cl) }\end{array}$ & $\begin{array}{l}\mathrm{P} \text { - } \\
\text { value }\end{array}$ & $\begin{array}{l}\text { Immediate } \\
\text { FET group }\end{array}$ & $\begin{array}{l}\text { Delayed } \\
\text { FET } \\
\text { group }\end{array}$ & $\begin{array}{l}\text { Relative } \\
\text { risk } \\
(95 \% \\
\text { Cl) }\end{array}$ & $\begin{array}{l}\mathrm{P} \text { - } \\
\text { value }\end{array}$ \\
\hline Subjects & 366 & 366 & & & 326 & 320 & & \\
\hline $\begin{array}{l}\text { Positive } \\
\text { pregnancy }\end{array}$ & $155(42.3)$ & $\begin{array}{l}159 \\
(43.4)\end{array}$ & $\begin{array}{l}0.98 \\
(0.83 \text { to } \\
1.15)\end{array}$ & 0.765 & $154(47.2)$ & $\begin{array}{l}157 \\
(49.1)\end{array}$ & $\begin{array}{l}0.96 \\
(0.82 \text { to } \\
1.13)\end{array}$ & 0.643 \\
\hline $\begin{array}{l}\text { Embryo } \\
\text { implantation }\end{array}$ & $\begin{array}{l}157 / 620 \\
(25.3)\end{array}$ & $\begin{array}{l}125 / 609 \\
(20.5)\end{array}$ & $\begin{array}{l}1.23 \\
(1.00 \text { to } \\
1.52)\end{array}$ & 0.046 & $\begin{array}{l}156 / 620 \\
(25.2)\end{array}$ & $\begin{array}{l}123 / 609 \\
(20.2)\end{array}$ & $\begin{array}{l}1.25 \\
(1.01 \text { to } \\
1.53)\end{array}$ & 0.038 \\
\hline $\begin{array}{l}\text { Clinical } \\
\text { pregnancy } \neq\end{array}$ & $137(37.4)$ & $\begin{array}{l}111 \\
(30.3)\end{array}$ & $\begin{array}{l}1.23 \\
(1.01 \text { to } \\
1.51)\end{array}$ & 0.042 & $136(41.7)$ & $\begin{array}{l}109 \\
(34.1)\end{array}$ & $\begin{array}{l}1.23 \\
(1.00 \text { to } \\
1.50)\end{array}$ & 0.045 \\
\hline $\begin{array}{l}\text { Biochemical } \\
\text { pregnancy } \\
\text { loss }\end{array}$ & $18(11.6)$ & $\begin{array}{l}48 \\
(30.2)\end{array}$ & $\begin{array}{l}0.39 \\
(0.24 \text { to } \\
0.63)\end{array}$ & $<.001$ & $18(11.7)$ & $\begin{array}{l}48 \\
(30.6)\end{array}$ & $\begin{array}{l}0.28 \\
(0.23 \text { to } \\
0.63)\end{array}$ & $\begin{array}{l}<.001 \\
0.001\end{array}$ \\
\hline $\begin{array}{l}\text { Clinical } \\
\text { pregnancy } \\
\text { loss }{ }^{\rrbracket}\end{array}$ & $15(10.9)$ & $\begin{array}{l}13 \\
(11.7)\end{array}$ & $\begin{array}{l}0.94 \\
(0.47 \text { to } \\
1.88)\end{array}$ & 0.850 & $15(11.0)$ & $\begin{array}{l}12 \\
(11.0)\end{array}$ & $\begin{array}{l}1.00 \\
(0.49 \text { to } \\
2.05)\end{array}$ & 0.996 \\
\hline $\begin{array}{l}\text { Total } \\
\text { pregnancy } \\
\text { loss }\end{array}$ & $33(21.3)$ & $\begin{array}{l}61 \\
(38.4)\end{array}$ & $\begin{array}{l}0.56 \\
(0.39 \text { to } \\
0.80)\end{array}$ & 0.001 & $33(21.4)$ & $\begin{array}{l}60 \\
(38.2)\end{array}$ & $\begin{array}{l}0.56 \\
(0.39 \text { to } \\
0.81)\end{array}$ & 0.001 \\
\hline $\begin{array}{l}\text { Ectopic } \\
\text { pregnancy }\end{array}$ & $2(1.3)$ & $5(3.1)$ & $\begin{array}{l}0.41 \\
(0.08 \text { to } \\
2.08)\end{array}$ & 0.448 & $2(1.3)$ & $5(3.2)$ & $\begin{array}{l}0.40 \\
(0.08 \text { to } \\
2.04)\end{array}$ & 0.448 \\
\hline $\begin{array}{l}\text { Multiple } \\
\text { pregnancy }\end{array}$ & $18(13.1)$ & $\begin{array}{l}14 \\
(12.6)\end{array}$ & $\begin{array}{l}1.04 \\
(0.54 \text { to } \\
2.00)\end{array}$ & 0.902 & $18(13.2)$ & $\begin{array}{l}14 \\
(12.8)\end{array}$ & $\begin{array}{l}1.03 \\
(0.54 \text { to } \\
1.98)\end{array}$ & 0.928 \\
\hline $\begin{array}{l}\text { Ongoing } \\
\text { pregnancy }\end{array}$ & $122(33.3)$ & $\begin{array}{l}98 \\
(26.8)\end{array}$ & $\begin{array}{l}1.25 \\
(0.99 \text { to } \\
1.56)\end{array}$ & 0.053 & $121(37.1)$ & $\begin{array}{l}97 \\
(30.3)\end{array}$ & $\begin{array}{l}1.22 \\
(0.99 \text { to } \\
1.52)\end{array}$ & 0.067 \\
\hline Live birth & $120(32.8)$ & $\begin{array}{l}96 \\
(26.2)\end{array}$ & $\begin{array}{l}1.25 \\
(0.99 \text { to } \\
1.57)\end{array}$ & 0.052 & $119(36.5)$ & $\begin{array}{l}96 \\
(30.0)\end{array}$ & $\begin{array}{l}1.22 \\
(0.98 \text { to } \\
1.52)\end{array}$ & 0.079 \\
\hline \multicolumn{9}{|c|}{$\begin{array}{l}\neq \text { In the Immediate FET group, one woman conceived naturally and delivered a healthy male infant } \\
\text { vaginally. }\end{array}$} \\
\hline $\begin{array}{l}\text { In the Dela } \\
\text { trimester be }\end{array}$ & ET group & wome & eive & tan & howe & e mis & in & cond \\
\hline
\end{tabular}


In the immediate FET group, 136 of 326 women (41.7\%) had a higher clinical pregnancy rate compared with 109 out of 320 (34.1\%) in the delayed FET group (RR 1.23, 95\% Cl 1.00-1.50, p = 0.045 for PP analysis).

Furthermore, the ITT and PP analyses yielded the same findings (37.4\% vs. $30.3 \%$, RR $1.23,95 \% \mathrm{Cl} 1.01-1.51$, $\mathrm{p}=0.042$; Table 2). The embryo implantation rate was $25.2 \%(156 / 620)$ in the immediate FET group and $20.2 \%(123 / 609)$ in the delayed FET group (RR 1.25, 95\% Cl 1.01-1.53, $p=0.038$ for PP analysis).

Additionally, the results of the ITT analysis were similar to the PP analysis ( $25.3 \%$ vs. $20.5 \%, \mathrm{RR} 1.23,95 \% \mathrm{Cl}$ 1.00-1.52, $p=0.046$; Table 2).

Biochemical pregnancy loss was more than two times frequent among individuals in the immediate FET than the delayed FET ( $30.2 \%$ vs. $11.6 \%, \mathrm{p}<0.001$ for ITT, and $30.6 \%$ vs. $11.7 \%, \mathrm{p}<0.001$ for PP analysis; Table 2 ). Nonetheless, there was no statistically significant difference in the rate of clinical pregnancy loss between the two groups. Nevertheless, total pregnancy loss per positive hCG test was approximately $80 \%$ higher in delayed FET cycles than immediate FET in the ITT analysis $(38.4 \%$ vs. $21.3 \%, p=0.001)$ and the PP analysis $(38.2 \%$ vs. $21.4 \%, p=0.001$ ) (Table 2 ). The $h C G$ positive pregnancy rate, multiple pregnancy rate, and ectopic pregnancy rate did not differ significantly between the two groups (Table 2). The detailed results of secondary outcomes on maternal and perinatal complications are presented in Supplementary Tables S4.

A multivariable logistic regression analysis was performed to adjust for potential confounding factors, and the results are presented in Table 3. The timing of initial FET after a failed fresh ET attempt had no significant effect on the positive pregnancy rate. Interestingly, after adjusting for a variety of confounding variables that may influence the success of frozen-thawed embryo transfer, we found that the timing of FET was an independent and significant factor in clinical pregnancy rate, ongoing pregnancy rate, and live birth rate (odds ratio [OR] 0.68, 95\% Cl 0.47-0.91, p = 0.031; OR 0.68, 95\% Cl 0.47-0.99, p = 0.041; OR 0.67, 95\% Cl 0.46-0.96, $p=0.031$, respectively; Table 3$)$. The other variables that had a significant effect on ongoing pregnancy rates were BMI, AFC, method of fertilization, and high-stress levels before FET (Table 4). Detailed logistic regression analyses of all pregnancy outcomes are shown in Supplementary Tables S1, S2, and S3. 
Table 3

Relationship between the timing of initial FET after a fresh IVF-ET attempt failure and pregnancy outcomes in different models.

\begin{tabular}{|c|c|c|c|c|c|c|c|}
\hline \multirow{2}{*}{$\begin{array}{l}\text { Pregnancy } \\
\text { outcomes }\end{array}$} & \multirow[t]{2}{*}{$\begin{array}{l}\text { Timing of } \\
\text { initial FET }\end{array}$} & \multicolumn{2}{|c|}{ Crude model $^{a}$} & \multicolumn{2}{|c|}{ Adjusted model $\nabla^{\beta}$} & \multicolumn{2}{|c|}{ Adjusted model $₫ \mathrm{Y}$} \\
\hline & & OR $(95 \% \mathrm{Cl})$ & $\begin{array}{l}P \\
\text { value }\end{array}$ & OR (95\% Cl) & $\begin{array}{l}P \\
\text { value }\end{array}$ & $\begin{array}{l}\text { OR }(95 \% \\
\mathrm{Cl})\end{array}$ & $\begin{array}{l}P \\
\text { value }\end{array}$ \\
\hline \multirow[t]{2}{*}{$\begin{array}{l}\text { Positive } \\
\text { pregnancy }\end{array}$} & $\begin{array}{l}\text { Immediate } \\
\text { FET group }\end{array}$ & Reference & & Reference & & Reference & \\
\hline & $\begin{array}{l}\text { Delayed FET } \\
\text { group }\end{array}$ & $\begin{array}{l}1.09 \text { (0.80to } \\
1.48)\end{array}$ & 0.587 & $\begin{array}{l}1.04(0.75 \\
\text { to } 1.44)\end{array}$ & 0.810 & $\begin{array}{l}0.95(0.67 \\
\text { to } 1.35)\end{array}$ & 0.781 \\
\hline \multirow[t]{2}{*}{$\begin{array}{l}\text { Clinical } \\
\text { pregnancy }\end{array}$} & $\begin{array}{l}\text { Immediate } \\
\text { FET group }\end{array}$ & Reference & & Reference & & Reference & \\
\hline & $\begin{array}{l}\text { Delayed FET } \\
\text { group }\end{array}$ & $\begin{array}{l}0.74(0.54 \\
\text { to } 1.02)\end{array}$ & 0.066 & $\begin{array}{l}0.70(0.50 \\
\text { to } 0.97)\end{array}$ & 0.031 & $\begin{array}{l}0.68(0.47 \\
\text { to } 0.97)\end{array}$ & 0.031 \\
\hline \multirow[t]{2}{*}{$\begin{array}{l}\text { Ongoing } \\
\text { pregnancy }\end{array}$} & $\begin{array}{l}\text { Immediate } \\
\text { FET group }\end{array}$ & Reference & & Reference & & Reference & \\
\hline & $\begin{array}{l}\text { Delayed FET } \\
\text { group }\end{array}$ & $\begin{array}{l}0.78(0.55 \\
\text { to } 1.05)\end{array}$ & 0.096 & $\begin{array}{l}0.71(0.51 \\
\text { to } 0.99)\end{array}$ & 0.048 & $\begin{array}{l}0.68(0.47 \\
\text { to } 0.99)\end{array}$ & 0.041 \\
\hline \multirow[t]{2}{*}{ Live birth } & $\begin{array}{l}\text { Immediate } \\
\text { FET group }\end{array}$ & Reference & & Reference & & Reference & \\
\hline & $\begin{array}{l}\text { Delayed FET } \\
\text { group }\end{array}$ & $\begin{array}{l}0.75(0.54 \\
\text { to } 1.04)\end{array}$ & 0.080 & $\begin{array}{l}0.70(0.50 \\
\text { to } 0.98)\end{array}$ & 0.038 & $\begin{array}{l}0.67(0.46 \\
\text { to } 0.96)\end{array}$ & 0.031 \\
\hline \multicolumn{8}{|c|}{$\begin{array}{l}\text { Abbreviation: AMH, anti-müllerian hormone; BMI, body mass index; FSH, follicle stimulating hormone; OR, } \\
\text { odds ratio; Cl, confidence interval; FET = frozen embryo transfer; IVF-ET, in vitro fertilization-embryo } \\
\text { transfer; AFC, antral follicle count; COS, controlled ovarian stimulation; Gn, gonadotropin. }\end{array}$} \\
\hline \multicolumn{8}{|c|}{$\begin{array}{l}{ }^{\beta} \text { Adjusted for female age ( }<35 \text { yrs., } \geq 35 \text { yrs.), moderate/severe depression prior to FET (yes, no), and } \\
\text { high stress level prior to FET (yes, no). }\end{array}$} \\
\hline \multicolumn{8}{|c|}{$\begin{array}{l}{ }^{Y} \text { Adjusted for female age (<35 yrs., } \geq 35 \mathrm{yrs} \text {.), AMH }(<1.2 \mathrm{ng} / \mathrm{ml}, \geq 1.2 \mathrm{ng} / \mathrm{ml}) \text {, BMI }\left(<24 \mathrm{~kg} / \mathrm{m}^{2}, \geq 24\right. \\
\left.\mathrm{kg} / \mathrm{m}^{2}\right) \text {, basic FSH }(<10 \mathrm{UI} / \mathrm{L}, \geq 10 \mathrm{UI} / \mathrm{L}), \mathrm{AFC}(<10, \geq 10) \text {, endometrial thickness before FET, No of } \\
\text { oocytes retrieved }(\leq 9,>9) \text {, No of transferred frozen thawed embryos (single, double), method of } \\
\text { fertilization (IVF, ICSI), moderate/severe depression prior to FET (yes, no), and high stress level prior to FET } \\
\text { (yes, no). }\end{array}$} \\
\hline
\end{tabular}


Table 4

Crude and adjusted odds ratio (OR) for timing of initial frozen embryo transfer (FET) after a failed fresh IVF-ET attempt and other potential confounders for ongoing pregnancy.

\begin{tabular}{|c|c|c|}
\hline Variable & Crude OR (95\% Cl) & Adjusted OR (95\% Cl) \\
\hline \multicolumn{3}{|c|}{ Timing of initial FET } \\
\hline Immediate & Reference & Reference \\
\hline Delayed & $0.78(0.55$ to 1.05$)$ & $0.68(0.47$ to 0.99$)$ \\
\hline \multicolumn{3}{|l|}{ Female age } \\
\hline <35 yrs. & Reference & Reference \\
\hline$\geq 35$ yrs. & 0.77 (0.52 to 1.12$)$ & $0.87(0.58$ to 1.31$)$ \\
\hline \multicolumn{3}{|c|}{ Anti-müllerian hormone (AMH) } \\
\hline$<1.2 \mathrm{ng} / \mathrm{ml}$ & Reference & Reference \\
\hline$\geq 1.2 \mathrm{ng} / \mathrm{ml}$ & 1.12 (0.68 to 1.83$)$ & $1.20(0.71$ to 2.03$)$ \\
\hline \multicolumn{3}{|c|}{ Body mass index (BMI) } \\
\hline$<24 \mathrm{~kg} / \mathrm{m}^{2}$ & Reference & Reference \\
\hline$\geq 24 \mathrm{~kg} / \mathrm{m}^{2}$ & $0.67(0.48$ to 0.94$)$ & $0.62(0.43$ to 0.89$)$ \\
\hline \multicolumn{3}{|l|}{ Basic FSH } \\
\hline$<10 \mathrm{UI} / \mathrm{L}$ & Reference & Reference \\
\hline$\geq 10 \mathrm{UI} / \mathrm{L}$ & $0.84(0.56$ to 1.26$)$ & $0.90(0.58$ to 1.40$)$ \\
\hline \multicolumn{3}{|c|}{ Antral follicle count (AFC) } \\
\hline$<10$ & Reference & Reference \\
\hline$\geq 10$ & $1.31(0.94$ to 1.83$)$ & 1.49 (1.05 to 2.12$)$ \\
\hline \multicolumn{3}{|c|}{ No of oocytes retrieved } \\
\hline$\leq 9$ & Reference & Reference \\
\hline$>9$ & 1.25 (0.86 to 1.82$)$ & 1.33 (0.88 to 2.02) \\
\hline \multicolumn{3}{|c|}{ Method of fertilization } \\
\hline IVF & Reference & Reference \\
\hline ICSI & $0.61(0.43$ to 0.87$)$ & $0.65(0.45$ to 0.95$)$ \\
\hline \multicolumn{3}{|c|}{ No of transferred frozen thawed embryos } \\
\hline Single & Reference & Reference \\
\hline Double & $1.68(0.92$ to 3.08$)$ & $1.33(0.70$ to 2.53$)$ \\
\hline
\end{tabular}




\begin{tabular}{|lcc|}
\hline Variable & Crude OR (95\% Cl) & Adjusted OR (95\% Cl) \\
\hline Endometrial thickness before FET & $1.09(0.99$ to 1.19) & $1.05(0.95$ to 1.16) \\
\hline Moderate/severe depression prior to FET & & \\
\hline No & Reference & Reference \\
\hline Yes & $0.75(0.40$ to 1.39$)$ & $0.70(0.36$ to 1.36$)$ \\
\hline High stress level prior to FET & Reference & Reference \\
\hline No & $0.27(0.17$ to 0.43$)$ & 0.28 (0.17 to 0.45) \\
\hline Yes & & \\
\hline Abbreviation: IVF-ET, in vitro fertilization-embryo transfer; Cl, confidence interval.
\end{tabular}

\section{Safety outcomes}

Overall, there were no apparent safety concerns. Eleven serious adverse events were reported among the study population, all of which were judged to be unrelated or unlikely to be related to the investigational procedure. These adverse events were hyperemesis $(n=1)$, ovarian torsion $(n=1)$, acute appendicitis $(n=1)$, heterotopic pregnancy $(n=7)$, and fetal malformations $(n=1)$.

\section{Discussion}

The results of this RCT revealed significantly higher embryo implantation and clinical pregnancy rates and a lower biochemical pregnancy loss rate in the immediate FET group than the delayed FET group. Although no significant differences in ongoing pregnancy and live birth rates were detected between the two groups, the binary multivariate logistic regression analysis revealed a significant difference in favor of the immediate FET group. The high-stress level before FET was also shown to affect the ongoing pregnancy rate.

FET has been increasingly performed in assisted reproductive technologies (ART) in the last few decades [1]. The development of controlled ovarian stimulation (COS) protocol has led to increased embryo freezing techniques and surplus embryos. The freeze-all policy was also established to overcome potential adverse carryover effects of COS $[2,14]$. However, two recent large randomized controlled studies did not find any significant difference between fresh ET and FET among infertile ovulatory women [28] or women without polycystic ovaries [29]. Therefore, some scholars argue that the residual effect of COS on endometrial receptivity on the next menstrual cycle is nonexistent. In addition, delayed FET could emotionally stress patients who may be eager to conceive as soon as possible, especially after a failed fresh ET cycle and, may lead to drop-out from infertility treatment [30]. Therefore, there is a need to avail evidence on the perfect timing of FET after COS.

Four previously conducted studies showed no difference in the live birth rate between delayed FET and immediate FET groups following a failed-fresh cycle [17, 20, 21, 30]. However, a study conducted by Volodarsky-Perel et al., using only GnRH agonist long protocol, reported contrasting results. The hormonal profile and function of the corpus luteum after oocyte pick-up differed between the GnRH agonist long 
protocol and $\mathrm{GnRH}$ antagonist protocol [22]. GnRH receptors were downregulated in the $\mathrm{GnRH}$ agonist long protocol, and the recovery of $\mathrm{GnRH}$ receptors took longer than the GnRH antagonist protocol. Also, hCG used in $\mathrm{GnRH}$ agonist long protocol had a longer half-life and could have impacted the function of the corpus luteal and endometrial receptivity of the subsequent cycle. Based on published literature, immediate FET after a failed fresh cycle was assumed to have less harm than delayed FET except in GnRH long protocol. However, these studies had several limitations. A study by Huang et al. did not include an adequate number of patients [30]. In addition, a study by Horowitz et al. had a possibility of practical bias [21].

A recent RCT showed that immediate FET improved ongoing pregnancy rates $(47.2 \%$ vs. $39.3 \%, p=0.03)$ and reduced the risk of miscarriage (11.2 vs. $19.7 \%, p=0.02)$ [31]. However, this study was limited as it included patients with a previous failed fresh ET and those who performed a freeze-all strategy. Moreover, the study had an unequal balance of subjects in terms of female age and number of oocytes retrieved, despite randomization. Furthermore, the RCT did not assess for depression and stress levels, thus it is unknown whether women who undergo delayed FET are more stressed than women who undergo immediate FET. A recent study determining attitudes towards elective FET in a freeze-all strategy showed that $59.2 \%$ of women and $59.7 \%$ of men would choose elective FET over fresh ET if the chances of pregnancy were the same [32]. Undergoing a delayed FET cycle is an emotional process for couples who have already experienced a delay in conception, especially for women who have experienced a failed fresh ET cycle. Delaying FET may be a potential source of ART-related stress to patients and a reason for treatment discontinuation [33]. Thus, one possible explanation for our results is the negative emotional state such as stress or depression of the delayed FET group.

In the present study, the frequency of moderate to severe depression and high-stress levels before FET in the delayed FET group was significantly higher than that in the immediate FET group. Moreover, logistic regression analysis also revealed the adverse effects of high-stress levels on ongoing pregnancy and live birth rates. Therefore, immediate FET is beneficial to alleviate psychological pressure on patients and shorten the time of pregnancy. When female mouse embryos were exposed with stress, the frequency of implantations dropped substantially and the percentage of apoptotic cells in blastocysts rose [34,35]. This may be because the stress response altered the endometrium's oxidative stress pathway, impairing endometrial remodeling; the increased production of oxidative stress molecules in serum and oviduct also impairs embryo development [36]. Other mechanisms may include a more favorable endometrial immune status after COS [37], while the corpora lutea producing high levels of vasodilatory and angiogenic factors during stimulation [38] could also have a positive effect in case of an immediate FET. However, it is not obvious that the multiple corpus luteum could produce a higher serum level of relaxin [39]. Further, it is not clear if higher serum levels of relaxin in a COS cycle could continue to the subsequent menstrual cycle. Therefore, further prospective clinical and translational studies are necessary to validate these findings and investigate the underlying mechanisms.

To the best of our knowledge, this is the first RCT determining the timing of FET following a failed fresh IVFET cycle. However, this study had some limitations. The primary outcome was the ongoing pregnancy rate determined as an intrauterine detectable fetal heartbeat after more than twelve gestational weeks. However, the live birth rate was also reported. We caution that this study only evaluated the effect of delayed and immediate FET on the ongoing pregnancy rate following HRT; thus, the results may not be extrapolated to 
other methods of endometrial preparation, such as natural cycle FET. Additionally, the multiple pregnancy rate remained high at more than $10 \%$ after the transfer of a maximum of two embryos. In the future, randomized studies comparing the live birth rate as the primary outcome following a single blastocyst transfer are needed.

\section{Conclusions}

In conclusion, the immediate FET group resulted in higher ongoing pregnancy and live birth rates and a lower biochemical pregnancy loss rate than the delayed FET group. These findings warrant caution in indiscriminately using delayed FET in patients with high-risk stress levels. This study recommends immediate FET following a failed fresh IVF-ET cycle to improve the live birth rate.

\section{Declarations}

\section{Acknowledgments}

We thank the clinical staff of the four reproductive centers for their help in the clinical work which made this study possible.

\section{Authors' contributions}

Zhen-Gao Sun and Jing-Yan Song conceived and designed this study. All authors made a significant contribution in the conception, study design, execution, data acquisition, analysis, and interpretation. Jing-Yan Song and Feng-Yi Dong took part in drafting, revising, or critically reviewing the article; and gave final approval of the version to be published; All authors approved the submission of this work to the Reproductive Biology and Endocrinology journal and agreed to be accountable for all aspects of this work.

\section{Funding}

This research did not receive any specific grant from funding agencies in the public, commercial, or not-forprofit sectors.

\section{Availability of data and materials}

The data generated and analyzed in this study will be availed upon request by the corresponding author.

\section{Ethics approval and consent to participate}

This study was conducted in accordance with the Declaration of Helsinki. The study was approved by the Ethics Committees of all participating hospitals. All participants provided written informed consent. Furthermore, the study was approved by the Ethics Committee of Assisted Reproductive Medicine at the Affiliated Hospital of Shandong University of TCM (SDTCM/E2020.2.01).

\section{Consent for publication}

Written informed consent for publication was obtained from all participants. 


\section{Competing interests}

The authors declare no competing interests.

\section{References}

1. Doody KJ. Cryopreservation and delayed embryo transfer-assisted reproductive technology registry and reporting implications. Fertil Steril. 2014;102:27-31.

2. Roque $M$, Valle $M$, Kostolias $A$, Sampaio $M$, Geber $S$. Freeze-all cycle in reproductive medicine: current perspectives. JBRA Assist Reprod. 2017;21:49-53.

3. Shapiro BS, Daneshmand ST, De Leon L, Garner FC, Aguirre M, Hudson C. Frozen-thawed embryo transfer is associated with a significantly reduced incidence of ectopic pregnancy. Fertil Steril. 2012;98:1490-4.

4. Shih W, Rushford DD, Bourne H, Garrett C, McBain JC, Healy DL, Baker HW. Factors affecting low birthweight after assisted reproduction technology: difference between transfer of fresh and cryopreserved embryos suggests an adverse effect of oocyte collection. Hum Reprod. 2008;23:1644-53.

5. Ishihara O, Araki R, Kuwahara A, Itakura A, Saito H, Adamson GD. Impact of frozen-thawed singleblastocyst transfer on maternal and neonatal outcome: an analysis of 277,042 single-embryo transfer cycles from 2008 to 2010 in Japan. Fertil Steril. 2014;101:128-33.

6. Kalra SK, Ratcliffe SJ, Coutifaris C, Molinaro T, Barnhart KT. Ovarian stimulation and low birth weight in newborns conceived through in vitro fertilization. Obstet Gynecol. 2011;118:863-71.

7. Pelkonen S, Koivunen R, Gissler M, Nuojua-Huttunen S, Suikkari AM, Hyden-Granskog C, Martikainen H, Tiitinen A, Hartikainen AL. Perinatal outcome of children born after frozen and fresh embryo transfer: the Finnish cohort study 1995-2006. Hum Reprod. 2010;25:914-23.

8. Clayton HB, Schieve LA, Peterson HB, Jamieson DJ, Reynolds MA, Wright VC. Ectopic pregnancy risk with assisted reproductive technology procedures. Obstet Gynecol. 2006;107:595-604.

9. Ishihara O, Kuwahara A, Saitoh H. Frozen-thawed blastocyst transfer reduces ectopic pregnancy risk: an analysis of single embryo transfer cycles in Japan. Fertil Steril. 2011;95:1966-9.

10. Maheshwari A, Pandey S, Shetty A, Hamilton M, Bhattacharya S. Obstetric and perinatal outcomes in singleton pregnancies resulting from the transfer of frozen thawed versus fresh embryos generated through in vitro fertilization treatment: a systematic review and meta-analysis. Fertil Steril. 2012;98:36877 e361-9.

11. Wennerholm UB, Henningsen AK, Romundstad LB, Bergh C, Pinborg A, Skjaerven R, Forman J, Gissler M, Nygren KG, Tiitinen A. Perinatal outcomes of children born after frozen-thawed embryo transfer: a Nordic cohort study from the CoNARTaS group. Hum Reprod. 2013;28:2545-53.

12. Weinerman R, Mainigi M. Why we should transfer frozen instead of fresh embryos: the translational rationale. Fertil Steril. 2014;102:10-8.

13. Devroey P, Polyzos NP, Blockeel C. An OHSS-Free Clinic by segmentation of IVF treatment. Hum Reprod. 2011;26:2593-7.

14. Roque M. Freeze-all policy: is it time for that? J Assist Reprod Genet. 2015;32:171-6. 
15. Wong KM, Mastenbroek S, Repping S. Cryopreservation of human embryos and its contribution to in vitro fertilization success rates. Fertil Steril. 2014;102:19-26.

16. Reichman DE, Chung P, Meyer L, Greenwood E, Davis O, Rosenwaks Z. Consecutive gonadotropinreleasing hormone-antagonist in vitro fertilization cycles: does the elapsed time interval between successive treatments affect outcomes? Fertil Steril. 2013;99:1277-82.

17. Maas KH, Baker VL, Westphal LM, Lathi RB. Optimal timing of frozen embryo transfer after failed IVF attempt Fertility and Sterility 2008, 90:S285.

18. Hu XL, Feng C, Lin XH, Zhong ZX, Zhu YM, Lv PP, Lv M, Meng Y, Zhang D, Lu XE, et al. High maternal serum estradiol environment in the first trimester is associated with the increased risk of small-forgestational-age birth. J Clin Endocrinol Metab. 2014;99:2217-24.

19. Diamond MP, Kruger M, Santoro N, Zhang H, Casson P, Schlaff W, Coutifaris C, Brzyski R, Christman G, Carr BR, et al. Endometrial shedding effect on conception and live birth in women with polycystic ovary syndrome. Obstet Gynecol. 2012;119:902-8.

20. Santos-Ribeiro S, Siffain J, Polyzos NP, van de Vijver A, van Landuyt L, Stoop D, Tournaye H, Blockeel C. To delay or not to delay a frozen embryo transfer after a failed fresh embryo transfer attempt? Fertil Steril. 2016;105:1202-7.

21. Horowitz E, Mizrachi Y, Farhi J, Shalev A, Raziel A, Weissman A. Modified natural-cycle cryopreserved embryo transfer: is a washout period needed after a failed fresh cycle? Reproductive Biomedicine Online. 2019;39:439-45.

22. Volodarsky-Perel A, Eldar-Geva T, Holzer HE, Schonberger O, Reichman O, Gal M. Cryopreserved embryo transfer: adjacent or non-adjacent to failed fresh long $\mathrm{GnRH}$-agonist protocol IVF cycle. Reproductive Biomedicine Online. 2017;34:267-73.

23. Liu Z, Dong F, Wang Y, Zheng M, Song M, Wang Y, Song J. A Comparison of the Efficacy of Immediate Versus Delayed Frozen-Thawed Embryo Transfer on the Ongoing Pregnancy Rate After a Failed IVF Attempt: Study Protocol for a Randomized, Non-Inferiority, Parallel-Group, Controlled Trial. Front Endocrinol (Lausanne). 2021;12:603158.

24. Bech P, Rasmussen NA, Olsen LR, Noerholm V, Abildgaard W. The sensitivity and specificity of the Major Depression Inventory, using the Present State Examination as the index of diagnostic validity. J Affect Disord. 2001;66:159-64.

25. Olsen LR, Mortensen EL, Bech P. Prevalence of major depression and stress indicators in the Danish general population. Acta Psychiatr Scand. 2004;109:96-103.

26. Cohen S, Kamarck T, Mermelstein R. A global measure of perceived stress. J Health Soc Behav. 1983;24:385-96.

27. Kolte AM, Olsen LR, Mikkelsen EM, Christiansen OB, Nielsen HS. Depression and emotional stress is highly prevalent among women with recurrent pregnancy loss. Hum Reprod. 2015;30:777-82.

28. Shi Y, Sun Y, Hao C, Zhang H, Wei D, Zhang Y, Zhu Y, Deng X, Qi X, Li H, et al. Transfer of Fresh versus Frozen Embryos in Ovulatory Women. N Engl J Med. 2018;378:126-36.

29. Vuong LN, Dang VQ, Ho TM, Huynh BG, Ha DT, Pham TD, Nguyen LK, Norman RJ, Mol BW. IVF Transfer of Fresh or Frozen Embryos in Women without Polycystic Ovaries. N Engl J Med. 2018;378:137-47. 
30. Huang J, Lu X, Xie Q, Lin J, Cai R, Kuang Y. Timing of frozen-thawed embryo transfer after controlled ovarian stimulation in a non-elective freeze-all policy. Ann Transl Med. 2019;7:752.

31. Li H, Sun X, Yang J, Li L, Zhang W, Lu X, Chen J, Chen H, Yu M, Fu W, et al. Immediate versus delayed frozen embryo transfer in patients following a stimulated IVF cycle: a randomised controlled trial. Hum Reprod. 2021;36:1832-40.

32. Stormlund S, Schmidt L, Bogstad J, Lossl K, Praetorius L, Zedeler A, Pinborg A. Patients' attitudes and preferences towards a freeze-all strategy in ART treatment. Hum Reprod. 2019;34:679-88.

33. Lancastle D, Boivin J. A feasibility study of a brief coping intervention (PRCl) for the waiting period before a pregnancy test during fertility treatment. Hum Reprod. 2008;23:2299-307.

34. deCatanzaro D, MacNiven E, Goodison T, Richardson D. Estrogen antibodies reduce vulnerability to stressinduced failure of intrauterine implantation in inseminated mice. Physiol Behav. 1994;55:35-8.

35. Janstova Z, Burkus J, Kubandova J, Fabian D, Koppel J, Cikos S. The effect of maternal stress on blastocyst quality depends on maternal physiological status. Gen Physiol Biophys. 2017;36:53-63.

36. Liu G, Dong Y, Wang Z, Cao J, Chen Y. Restraint stress delays endometrial adaptive remodeling during mouse embryo implantation. Stress. 2015;18:699-709.

37. Junovich G, Mayer Y, Azpiroz A, Daher S, Iglesias A, Zylverstein C, Gentile T, Pasqualini S, Markert UR, Gutierrez G. Ovarian stimulation affects the levels of regulatory endometrial NK cells and angiogenic cytokine VEGF. Am J Reprod Immunol. 2011;65:146-53.

38. Conrad KP, Baker VL. Corpus luteal contribution to maternal pregnancy physiology and outcomes in assisted reproductive technologies. Am J Physiol Regul Integr Comp Physiol. 2013;304:R69-72.

39. Arthur ID, Anthony FW, Adams S, Thomas EJ. Serum relaxin and the major endometrial secretory proteins in in-vitro fertilization and down-regulated hormone-supported and natural cycle frozen embryo transfer. Hum Reprod. 1996;11:88-91.

\section{Figures}


1212 candidates undergoing initial consultation and screening

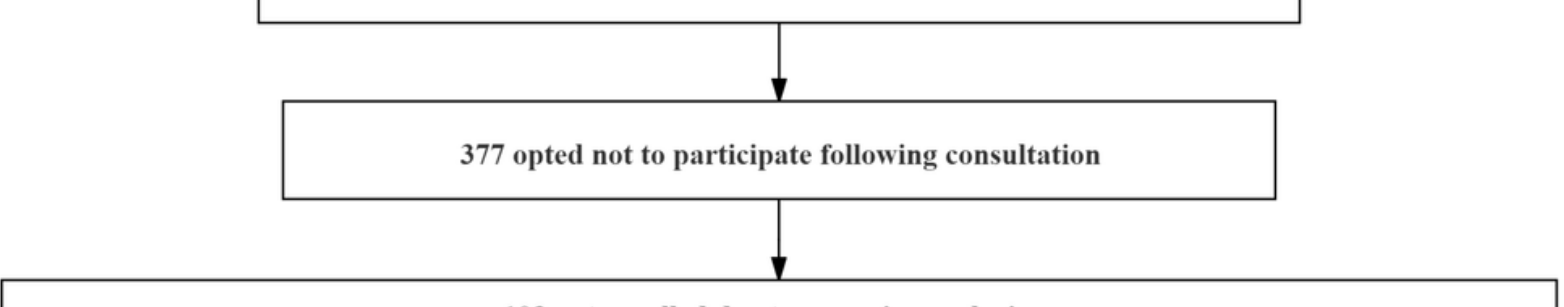

103 not enrolled due to screening exclusions

27 Body Mass Index $(\mathrm{BMI}) \geq 28 \mathrm{~kg} / \mathrm{m}^{2} ; 14 \mathrm{BMI}<18 \mathrm{~kg} / \mathrm{m}^{2} ; 14$ Fresh embryo transfer cancelled for asynchronous endometrium, unexpectedly elevated progesterone, and personal reasons; 12 Using the natural cycle or mild stimulation for IVF/ICSI treatment; 2 Severe hyperstimulation ovarian syndrome; 10 No remaining embryos available for FET; 3 A history of unilateral oophorectomy; 5 Recurrent pregnancy loss; 3 Spontaneous pregnancy; 3 In vitro Maturation; 3 Embryos cryopreserved at external facility; 3 blastocyst biopsy for PGD or PGT-A; 4 Abnormal pap or results available

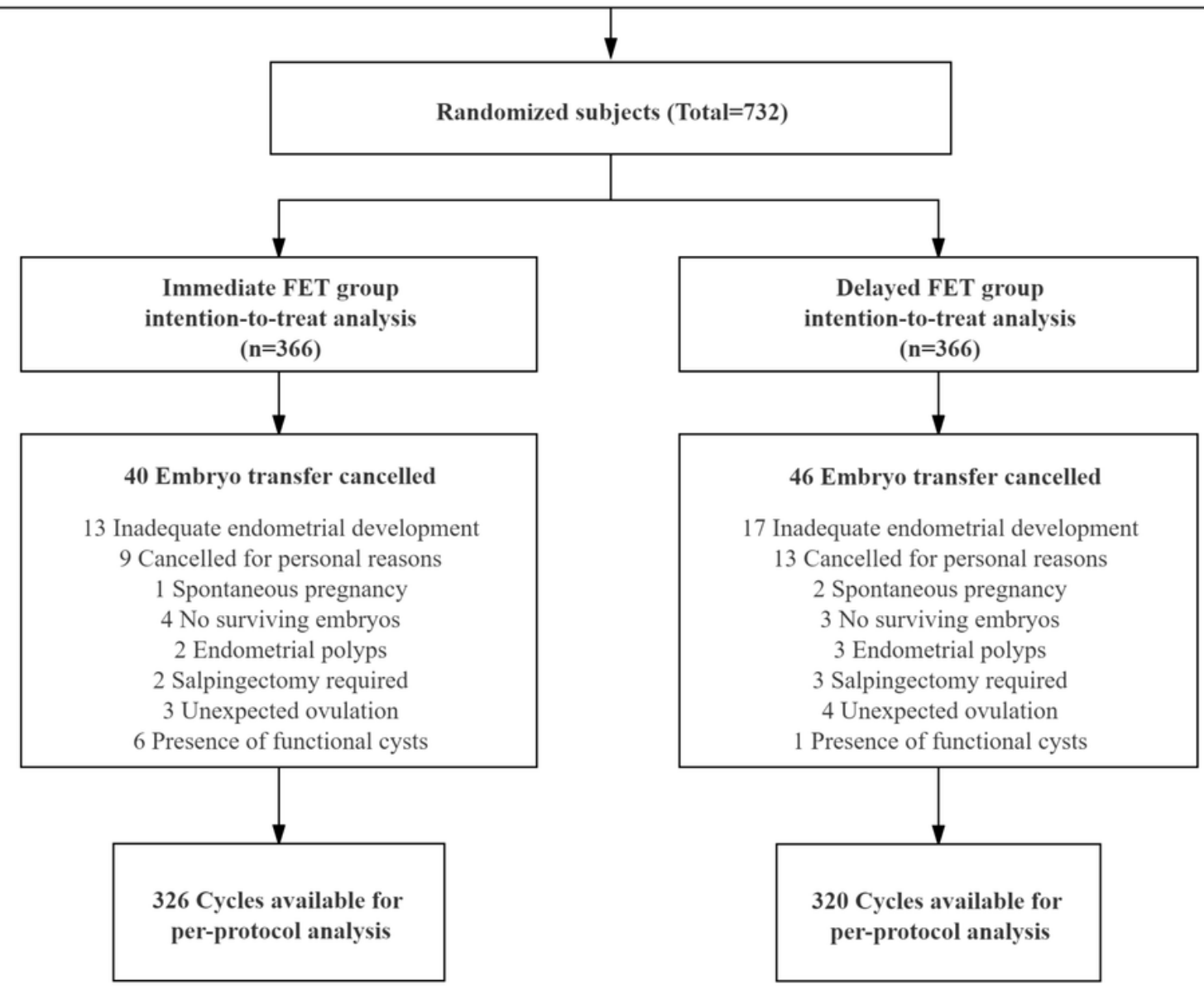

\section{Figure 1}

CONSORT diagram: summary of study screening and enrollment, embryo transfer cancellation, and completions per protocol by immediate and delayed FET groups. (FET=frozen-thawed embryo transfer; IVF=in vitro fertilization; ICSI=intracytoplasmic sperm injection; PGD=preimplantation genetic diagnosis; PGT-A= preimplantation genetic testing for aneuploidy)

\section{Supplementary Files}


This is a list of supplementary files associated with this preprint. Click to download.

- SupplementaryTables.docx 